\title{
O PROCESSO REVOLUCIONÁRIO DE 30 EM SANTA CATARINA
}

\section{Carlos Humberto Correa}

A efetiva oposição catarinense ao governo oligárquico de Hercílio Luz teve início quando Nereu Ramos, reeleito Deputado estadual em 1919 pela minoria, juntamente com seu primo Aristiliano Ramos, pretende uma vaga na Câmara Federal, apoiado por seu pai, o Senador Vidal Ramos. Este, para alcançar tal objetivo, incentiva o nome do político joinvillense Abdon Batista para concorrer ao governo estadual com o tradicional e cada vez mais fortalecido chefe do Partido Republicano, Hercílio Luz.

Derrotado de suas pretenções, Nereu participa, em 1927, no Rio de Janeiro, da fundação do Partido Democrático Nacional ao lado de Assis Brasil, Batista Luzardo e inúmeros outros representantes de vários estados.

No mesmo ano os democráticos se organizam em Santa Catarina e, pouco depois, os mesmos políticos fundam a Reação Republicana.

Em 1929 aliam-se aos liberais gaúchos, mineiros e paraibanos e passam a apoiar a candidatura Getúlio Vargas-João Pessoa em Santa Catarina. Ao lado de Nereu, na Aliança Liberal, aparece outro líder político do planalto central, Henrique Rupp Júnior.

A influência gaúcha no planalto catarinense, onde os seus interesses se confundiam com os dos catarinenses, na pecuária, era cada vez maior, aliada ao fato de que a maioria dos filhos dos estancieiros daquela região terem como única opção irem estudar em colégios gaúchos ao lado dos futuros lideres do Rio Grande. Entretanto, se os objetivos politicos maiores coincidiam, as rivalidades internas também eram refletidas no seio dos grupos catarinenses e gaúcho. Assim, se a liderança intelectual, dos aliancistas era mantida por Nereu Ramos, ligado a João Neves da Fontoura e Lindolfo Collor, ela era dividida com Henrique Rupp Júnior, do grupo de Osvaldo Aranha e Antunes Maciel, ao mesmo tempo que Aristiliano Ramos, lider político inconteste do planalto, era mais íntimo de Flores da Cunha e Getúlio Vargas, cujos pais eram compadres.

Conseqüentemente, os problemas gaúchos batiam diretamente em Santa Catarina, como foi o caso do desejo de Nereu Ramos de ser o primeiro Interventor Federal em Santa Catarina, cargo prometido por João Neves da Fontoura, 
então Vice-Presidente gaúcho, mas que, por ter sido afastado desta posição em favor de Osvaldo Aranha para governar o Estado quando da saida de Getúlio Vargas, fez com que Nereu perdesse a oportunidade politica em sua terra natal.

Santa Catarina tinha tido eleições para Presidente do Estado em 1929 e, em substituiçao a Adolpho Konder, ex-secretário de Hercílio Luz, eleito para o Senado, subiu as escadas presidenciais o político Fulvio Aducci, do grupo de Adolpho, que vai tomar posse nos fins de setembro de 30 . Poucos dias, então, de deflagração da Revolução.

O Governo catarinense ofereceu total oposição à consecução da Revolução em seu Estado.

Para alcançarem a Capital da República, os gaúchos tinham que atravessar Santa Catarina e garantirem o estabelecimento de um governo revolucionário, apesar dos obstáculos apresentados por Fulvio Aducci e pelas tropas militares ali sediada.

Enquanto Getúlio Vargas corta o Estado pelo meio Oeste por via ferroviária, forma-se uma coluna comandada pelo general Ptolomeu de Assis Brasil para tomar a capital catarinense, pelo litoral; outra, em Lages, que desceria a serra com o mesmo objetivo e sob o comando de Aristiliano Ramos e Octacilio Fernandes, e uma terceira, tendo por origem a cidade de Mafra. Entretanto, é bem provável que estas três não tivessem conhecimento mútuos.

No sul do Estado instalava-se um Governo Provisório, com sede em Tubarão e jurisdição sobre toda a região com o objetivo de assegurar o domínio revolucionário. Coube a Ernesto Lacombe, com a autorização de Osvaldo Aranha, a direção deste governo que inclusive emitiu dinheiro para garantir o suprimento das tropas que se dirigiam para Florianópolis.

O governo legalista reage ao avanço dos revoltosos e é deslocado para Florianópolis o comandante da Região Militar com sede em Curitiba, General Nepomuceno Costa, apoiado por uma esquadra da Marinha de Guerra brasileira comandada pelo Almirante Belfort de Matos, que constantemente bombardeia as tropas revolucionárias.

$\mathrm{O}$ avanço da coluna revolucionária em direção a Florianópolis apesar da forte resistência militar, só teve um encontro sangrento com tropas do Governo na garganta da Serra de Anitápolis, no hoje município do mesmo nome, quando tombaram alguns militares e foram presos perto de meia centena deles.

Em Blumenau instalou-se um Governo revolucionário alheio às chefias políticas e militares catarinenses, sob a alegaçao de haver sido, para tanto, nomeado pelo comandante militar do Paraná. Imediatamente telegramas de protestos de parte dos lideres aliancistas catarinenses são remetidos a Getúlio Vargas, que já se encontrava no Paraná, e a Osvaldo Aranha, Presidente interino do Rio Grande. Em conseqüência, tal Governo, que se afirmava legal e irredutível, é desautorizado pelos revolucionários e seu titular, o capitão A. 
Mancebo, retorna ao estado paranaense sob a alegação de acompanhar Getúlio Vargas. Tal fato vem apresentar a primeira reação catarinense a um governo alheio às suas hostes, fato que vai se repetir outras vezes ao longo do processo revolucionário.

Ante o fracasso das tropas legalistas o Presidente Fulvio Aducci e todos os seus auxiliares fogem da capital por via maritima e a 25 de outubro, vinte e dois dias após deflagrada a Revolução no Rio Grande do Sul, as tropas revolucionárias entram na capital catarinense.

Coube ao General Ptolomeu de Assis Brasil as rédeas da Interventoria, após a recusa de Vidal Ramos, e a Nereu Ramos a direção política dos liberais no Estado, auxiliado por Henrique Rupp Júnior, também revolucionário, mas seu antigo adversário particular.

Equacionados os primeiros problemas de ordem legal no Estado, com a Aliança Liberal tendo se transformado em Partido, reacendem as antigas rivalidades entre Nereu e Rupp, forçando este a fundar a Legião Republicana Catarinense, em oposição ao Partido Liberal, órgão oficial, mas ainda num velado apoio ao Interventor que gradativamente vai se transformar numa acirrada oposição à administração e a todas as pretensões da familia Ramos.

Além dos objetivos nacionais propugnados pela Aliança Liberal constantes do programa divulgado em 1929 à Nação brasileira, o Partido Liberal de Santa Catarina, em ordem estadual, defendia mais a educação pública extensa e intensa, o referendum popular, a publicidade ampla dos gastos oficiais, a supressão do imposto de exportação, a autonomia municipal, a absoluta independência do poder judiciário, o combate às oligarquias e à intromissão dos juizes na politica. Por seu lado, a Legião Republicana Catarinense, em Manifesto lançado em junho de 1931 através de seu órgão oficioso, "A Pátria", discorre sobre problemas econômicos, trabalho e capital, nacionalização, produção, sindicalismo, etc., mas que podem ser simplificados no combate sem tréguas ao personalismo e às oligarquias também, numa atividade coordenadora dos esforços individuais para a consolidação dos "verdadeiros objetivos da Revolução de outubro de 1930". Assim, abrangendo teoricamente problemas nacionais, ela pouco ou quase nada se distanciou do Partido Liberal, em seus objetivos regionais, com excessão das inimizades pessoais entre seus líderes.

Com a eclosão da Revolução Constitucionalista de São Paulo, Nereu Ramos a ela adere, renunciando a presidência do Partido Liberal, o quẹ também fazem outros membros da diretoria mais em seu apoio pessoal do que aos paulistas ou à Frente Unica riograndense. Com isto, a agremiação passa a ver sua força política declinar.

O Interventor, General Assis Brasil, de tendências constitucionalistas freqüentemente denunciadas, pouco faz para arregimentar tropas que deveriam seguir para São Paulo e combater os insurretos, além daquilo estritamente necessário e por obrigação do cargo que ocupa.

No interior do Estado, pequenos movimentos eclodem, liderados por anti- 
gos republicanos, mas são facilmente controlados.

Henrique Rupp Júnior, apesar de hipotecar solidariedade a Getúlio Vargas, continua combatendo a interventoria, dos Ramos,e é preso por motivos não justificados mas explicados pelo movimento paulista. Áristiliano Ramos. do planalto, também segue Getúlio.

Alegando doença e a necessidade de ter que se afastar constantemente do Governo para tratar de assuntos particulares no Rio Grande do Sul, Assis Brasil renuncia a Interventoria, ante a visivel alegria de todos os grupos catarinenses. A Legião Repubicana, indica uma série de nomes para substituí-lo, exigindo sempre que o novo Interventor seja um catarinense, e a figura de José Boiteux, republicano de formação e conviç̧ão, do antigo grupo hercilista, aparece em primeiro plano, para ser nomeado, como figura neutra aos meios revolucionários beligerantes entre si. Ante esta possibilidade, Assis Brasil retira sua renúncia e se conserva no governo por mais algum tempo até que seja nomeado um seu irmão, o Major Ruy Zobaran, de tendências caracteristicamente tenentistas.

A revolta pelo processo sucessório é geral e todas as tendências políticas no Estado se pronunciam desfavoravelmente. Sua posse é noticiada em poucas linhas, em páginas secundárias, pela Imprensa local.

Do Rio Grande do Sul, o Interventor Flores da Cunha pede para Getúlio a exoneração de Zobaran, mostrando a face constitucionalista da família, e exige a nomeação de seu amigo Aristiliano Ramos, condição para que ele também não se afaste do Governo gaúcho.

A função de Zobaran, é anular as forças políticas do Partido Liberal, da Legião Republicana e do Partido Republicano, que apesar de estar na clandestinidade, dava mostras da ascenção pelo retorno ao Brasil de Vitor Konder, irmão do ex-presidente do Estado e ex-ministro de Washington Luiz.

Para tanto, o Secretário do Interior e Justiça da Interventoria, Manoel Pedro da Silveira, funda o Partido Social Evolucionista, entidade que pretende aglutinar as mais fortes forças políticas do Estado, sob a tutela da Interventoria Federal. O Partido Social Evolucionista, integrado por elementos que se viram prejudicados com o transcorrer dos acontecimentos políticos, em Manifesto lançado em fevereiro de 1933, propunha-se, como as demais agremiações políticas, "amparar, proteger, prestigiar e consolidar a grande obra revolucionária". Entretanto, a força política almejada pelo Partido não passou da pretenção, pois limitou sua influência ao sul do Estado.

Durante o pequeno periodo governamental de Ruy Zobaran, salienta-se, ainda, a fundação do Clube 3 de Outubro em Santa Catarina. Entretanto, esta entidade tenentista pouca ou nenhuma importância teve no Estado.

Do periodo, ainda, tivemos o resurgimento do Partido Republicano Catarinense, organização que desde há muito se preparava para se relançar na arena política revolucionária, contando com o seu prestígio histórico, pois "victo- 
rioso o movimento revolucionário de 1930 e substituida a ordem legal por um governo de facto, que, por natureza e origem, prescinde, ao menos na phase inicial, da consulta ao eleitorado independente, nada mais restava ao Partido Republicano Catharinense, também arrastado na queda das instituições, sinão retrahir-se, licenciando os soldados e ensarilhando as armas de combate", segundo a introdução de seu Manifesto lançado também em fevereiro de 1933. Esquecendo-se, talvez. da estrutura eleitoral vigente durante a primeira República, quando a validade das eleições era duvidosa e, consequentemente, o regristro eleitoral não era obrigatório. O Partido Republicano Catarinense propunha basicamente o retorno do pais à normalidade legal condicionada à pré-existência de uma masșa eleitoral. "Nem outro recurso pacífico existe, nem outro processo sabemos - para, sem novos e violentos abalos, conduzir a Nação à posse de si mesma", concluiam os republicanos em seu Manifesto assinado pelos políticos derrotados em 30 .

Entretanto, as pressões internas e externas (Flores da Cunha) se tornavam cada vez maiores no sentido da renúncia de Zobaran. E talvez, mais do que a própria força dos políticos catarinenses neste sentido, novámente vemos a influência do Interventor gaúcho triunfar com a nomeação, para Interventor de Santa Catarina, do Coronel Aristiliano Ramos, lider revolucionário da região da serra.

Aproximam-se as eleições para a Constituinte Nacional onde irão concorrer cinco agremiações políticas: a Legião Republicana, o Partido Republicano, Partido Social Evolucionista, Partido Liberal Catarinense e a Liga Pró-Estado Leigo. Esta última era integrada por maçons e espiritas e, dentre outras coisas, propugnava pela separação completa entre a Igreja e o Estado, proibindo a obrigatoriedade do ensino religioso nas escolas.

As eleições transcorrem normalmente a 3 de maio de 1933 com um total de vinte candidatos para cinco vagas. Entretanto, por problemas técnicos, o Tribunal Eleitoral anulou o pleito.

No sentido de fortalecerem seus candidatos, a Legião Republicana e o Partido Republicano Catarinense assinam um acordo no qual unem seus candidatos para as novas eleições, sob o título de "Por Santa Catarina", com direção dupla: Adolpho Konder, pelos republicanos, e Rupp Júnior, pelos legionários.

A 3 de dezembro do mesmo ano os eleitores vão às urnas agora para escolherem outros candidatos, pois as listas são refeitas. Representavam somente três partidos: Por Santa Catarina, Partido Social Evolucionista e Partido Liberal Catarinense, visto que a Liga Pró-Estado Leigo, tendo em vista o resultado das eleições anuladas, resolveu não entrar na nova disputa.

O resultado é uma vitória flagrante dos liberais que elegem três candidatos, entre eles Nereu Ramos, enquanto que os da coligação Por Santa Catarina conseguem enviar para a Constituinte somente o ex-presidente do Estado, Adolpho Konder. Os evolucionistas não elegem ninguém.

No início de 34 nova agremiação política aparece, sô que com maior apro- 
fundamento ideológico: o Integralismo, que em Santa Catarina encontra fértil campo para a propagação de suas idéias, principalmente nas regiões historicamente de colonização germânica e italiana, como o vale do Itajai e o norte e nordeste do Estado, com Blumenau e Joinville como principais centros. O Integralismo cresce a olhos vistos no Estado de Santa Catarina, principalmente, com as constantes visitas de seu chefe nacional Plinio Salgado, quando reúne milhares de adeptos camisa-verdes em passeatas públicas pelas diversas cidades em que passa, incluindo homens, mulheres e grande número de crianças que participam da Juventude Integralista. A propaganda do movimento, se não é apoiada pelo interventoria, o é por muitas prefeituras, onde é aberta e pública, com colunas diárias em alguns jornais da capital e através de outros órgãos de divulgação específica nas outras cidades de maior número de adeptos.

Aproximam-se as novas eleições, que são realizadas a 14 de outubro, para representantes na Assembléia Estadual e no âmbito federal. Apesar de propugnarem pela queda do regime representativo, os integralistas apresentam candidatos para as duas áreas a fim de, segundo eles, provarem a nulidade do sistema do voto.

Desta vez a campanha da coligação Por Santa Catarina, agora aliada também aos membros do Partido Social Evolucionista, alcança seus objetivos, obtendo a maioria dos votos sobre os liberais no âmbito estadual e perdendo para a representação federal. Os integralistas ficam em terceiro lugar, a ninguém elegendo.

Caberia na instalação da Constituinte Estadual a eleição do Governador, caindo a data para inícios de março de 35 .

O Interventor Aristiliano Ramos era candidato natural ao governo como foram quase todos os interventores dos demais estados. Entretanto, o deputado federal Nereu Ramos também lança sua candidatura, o que vai dar início a uma das maiores lutas desenvolvidas nos bastidores da política de Santa Catarina. Ambos, irredutiveis, passam a usar dos variados triunfos através de influências diversas, principalmente junto aos ministros Vicente Rao e Antunes Maciel, além do interventor Flores da Cunha. A situação agrava-se e prenuncia-se uma cisão completa dos liberais em Santa Catarina, principalmente dentro da família Ramos, que até agora vinha aparentemente unida, pela disputa entre os dois primos.

Na tentativa de solucionar o impasse, aparece o nome de Álvaro Catão, antigo republicano do sul do Estado, que não é aceito pelos dois outros candidatos. Propõe-se, finalmente o arbítrio de Getúlio Vargas, que se nega a se meter na briga catarinense, pois apesar de apoiar Aristiliano, vê que ante a possibilidade da eleição de Nereu, inimigo de Flores da Cunha, poderá oferecer obstáculo às perigosas atitudes do interventor gaúcho.

Os evolucionistas que haviam corrido junto à coligação Por Santa Catarina, rompem com o compromisso assumido com Rupp e Konder, exigindo liberdade na escolha do Governador.

Agora com minoria, os coligados afastam-se publicamente da disputa mas 
incentivam a luta entre os liberais e resolvem não participar da eleição através do não comparecimento à Assembléia.

Cada candidato necessitava de 18 votos para ser eleito. Em principio, Nereu contava com 15 . Na última hora, ele conseguiu mais três, de deputados da Coligação, e foi eleito Governador. A imprensa falou em traição; Aristiliano revoltou-se e se aliou com Adolpho Konder, e Getúlio aceitou o resultado, pois segundo ele, se o Interventor não venceu, com todos os seus poderes inerentes ao cargo, não merecia seu apoio.

Nereu Ramos permanece como Governador até o golpe de 37. Gradativamente ele põe em prática seu plano de nacionalização do ensino das áreas de colonização não portuguesa, pois desde 1917, através do Jornal "O Dia», e mesmo pouco mais tarde, pelo seminário "A Noite", sempre desenvolveu a teoria da nacionalização nas áreas de colonização. Em 1937, com a força de um Interventor do Estado Novo, proíbe o ensino das línguas germânicas e italiana em território catarinense, combate, o Integralismo e levanta contra si a oposição política da região do Vale do Itajai, liderada por Adolpho Konder. 